\title{
The integration of a viscosity simulator in a chemistry laboratory
}

\author{
Maria Limniou $^{a *}$, Nikos Papadopoulos ${ }^{b}$, Andreas Giannakoudakis $^{b}$, David Roberts ${ }^{c}$ \\ and Oliver Otto ${ }^{\mathrm{c}}$
}

${ }^{a}$ School of Chemistry, The University of Manchester, UK

${ }^{b}$ Department of Chemistry, Aristotle University of Thessaloniki, Greece

${ }^{c}$ The Centre for Virtual Environments, University of Salford, UK

e-mail: Maria.Limniou@manchester.ac.uk

Received 2 June 2006, accepted 23 February 2007

\begin{abstract}
We integrated an interactive viscosity simulator into a pre-laboratory session in an attempt to improve training in a chemistry laboratory. The students were divided into two groups, the experimental group (EG) and the control group (CG). The students of the EG participated in a pre-laboratory session with additional instruction, including the use of the simulation on personal computers and other discussions. After the pre-labs, these students participated in the design of the experiments using the simulator as an educational tool, and then carried out the experiments; in addition, they processed their data on spreadsheets, and they pooled their results through a Local Area Network (LAN). Students of the CG performed the experiments following the traditional teaching procedure (recipe-labs), without attending the pre-lab session. Comparison of the two groups showed that the EG students valued the opportunity to question the teacher in the pre-laboratory session, and that they found this teaching procedure useful. As a result they felt more confident when they entered a laboratory and they understood better the theory behind the experiment than the CG students. [Chem. Educ. Res. Pract., 2007, 8 (2), 220-231.]
\end{abstract}

Keywords: chemistry laboratory, simulations, viscosity simulator, interactive learning environments, cooperative/collaborative learning, teaching/learning strategies

\section{Introduction}

Chemistry is an experimental science and its development and application demand a high standard of experimental work. Laboratory practice is expensive in terms of equipment, consumables and the time of academic and technical staff (Bennett and O'Neale, 1998) and it should help the students obtain technical skills such as manipulation, observations, data collection, processing and analysis of data, interpretation of observation, problem solving, team work, experiment design, communication skills etc. (Bennett and O'Neale, 1998; Johnstone and Al-Shuali, 2001). Additionally, during every laboratory session, the students receive a huge amount of information, such as the location of chemicals, recognition of equipment and the associated handling, instrumentation and safety requirements in a laboratory environment etc. (Johnstone, 1997b), and they can process only a few elements of current information at any given time (Gabel, 1999; Johnstone, 2000). Moreover, the quite large number of students can cause difficulties to the academic and technical staff, and as a result most teachers use 'recipes labs' and follow the traditional way of chemistry laboratory education (Domin, 1999). As Garratt (1997) has pointed out, using such 'recipe labs' is an effective strategy for maximising both the quantity of practical experience gained by students and quality of their results. However, 'recipes labs' do not provide opportunities to learn about experimental design, investigation, critical analysis of results, and sources of error. 
Students who are following a recipe lab are not 'doing an experiment', but 'carrying out an exercise', because they usually follow instructions mechanically, line-by-line, without thinking (Clow and Garratt, 1998). In order to improve chemistry education, many researchers, following constructivist theory, advocated teaching procedures that would help students understand the subject better (Bodner, 1986; Shiland, 1999; Towns, 2001).

In 1997 Johnstone claimed that there is 'no point in putting a student into a laboratory without mental preparation', and that 'the nature of the preparation has to be as carefully thought out as the course itself' (Johnstone, 1997a). Today the necessity for some kind of prelaboratory preparation is obvious, and many researchers use IT for this purpose (Ritter and Johnson, 1997; Clow and Garratt, 1998; Nicholls, 1999; Robinson, 2000). The simulator is a computer-based program that gives students access to more facilities that they otherwise would have. For example, students can discover concepts through guided inquiry using the simulation modules (Fermann, et al., 2000) and/or can be trained in the operation of instruments (Waller and Foster, 2000). Furthermore, the use of a simulator reduces the purchase and maintenance costs of the laboratory equipment, while enabling students to perform a variety of experiments in data collection and analysis (Thomas and Neilson, 1995).

The objectives of this investigation were to find ways for students

a. to be familiarized with the theory behind the laboratory activity,

b. to feel more confident when they enter a chemical laboratory,

c. to obtain the necessary experience in order to process and analyse experimental data using

Information Technology and

d. to work together as a team.

In order to help achieve these goals the students attended a pre-laboratory session before they entered a real laboratory. To verify whether this approach can assist the students to understand the chemical topics better than the traditional one, we used as reference another group of students who performed the same experiments in a chemistry laboratory following the traditional methods.

\section{Methodology}

\section{Assumption}

According to constructivism, every student 'fits' the new knowledge to what he/she already knows and constructs new knowledge accordingly (Bodner et al., 2001). In our investigation, we wanted all the students to have the same prior knowledge, which was considered to be the determination of mass, volume, mole fraction and concentration $(\% \mathrm{v} / \mathrm{v}$ and $\% \mathrm{w} / \mathrm{w}$ ). Thus, one week before conducting the course, we informed the students that this knowledge was necessary, so that they could prepare themselves for the viscosity experiment. The teacher assumed that the students' prior knowledge was well established in their minds, as it had been previously taught in high school and in their first year undergraduate courses.

\section{Participants and the experimental condition}

The course was conducted for two semesters in a physical chemistry laboratory in the Department of Chemistry of the Aristotle University of Thessaloniki in Greece, and the students were divided into two groups, the experimental group (EG) and the control group (CG).

\section{Experimental Group (EG)}

The students of the EG (18 male, 26 female) attended the pre-laboratory session and performed virtual experiments using the viscosity simulator. After that they entered the 
laboratory and performed the same experiments for real. The total time of pre-laboratory session and laboratory session was three hours.

In the pre-laboratory session, the students were divided into two-person teams who worked on a personal computer with the simulation program. The teams shared measurements, observations and conclusions about the virtual experiments with the other teams through the Local Area Network (LAN), after processing and analysing data. A LAN is a computer network covering a local area for example a classroom in which two or more computers are connected together using a telecommunication system for the purpose of communicating and sharing resources.

At the end of the laboratory session, we distributed a questionnaire to these students in order to assess their chemical knowledge about viscosity and discover their opinions about the pre-laboratory session.

\section{Control Group (CG)}

The students of the CG (16 male and 28 female students), performed the experiments only in a laboratory and they did not attend any pre-laboratory session. We explained the theory underlying the experiment to this group briefly, and we used 'recipes labs' in the traditional way. At the end of the laboratory session, we distributed to these students a questionnaire in order to assess their chemical knowledge about viscosity and to get their opinions about the laboratory training. The total time of laboratory session was three hours.

\section{Educational tool - Educational software}

During the pre-laboratory session, the viscosity simulator was used as an educational tool. The program was implemented in the 16-bit version of Microsoft Visual Basic 4.0. The software runs under Microsoft Windows 95, 98, 2000 and XP and is packaged on a CD-ROM (Papadopoulos et al., 1999). The design of this simulator is based on the cognitive load theory (Preece et. al., 1994; Quinn and Wild, 1998). Robinson (2002) has synoptically referred to the basic aspects of cognitive theory which are necessary to design a multimedia application. Pollock, Chandler and Sweller (2002) have pointed out that cognitive load theory uses some aspects of human cognitive architecture as well as the structure of information to provide instructional designs that facilitate understanding, learning and problem solving. The theory assumes the following.

1. The human cognitive system consists of two distinct channels for representing and controlling knowledge: an auditory-verbal channel and a visual-pictorial channel (Mayer and Moreno, 2002).

2. A limited working memory can process only a few elements of current information at any given time (Johnstone 1997b; Gabel, 1999). Thus, the visual-pictorial channel can be overloaded if too many pictures (or other visual material) are presented at one time. Similarly, the auditory-verbal channel can be also overloaded. Overloading one channel results in limiting the processing ability of the other one (Mayer and Moreno, 2002).

3. Active processing within the auditory-verbal and visual-pictorial channels leads to meaningful learning. Active processing includes organising relevant words and pictures into coherent pictorial and verbal models. The integration of the two channels together with previously obtained knowledge subsequently occurs (Mayer and Moreno, 2002).

4. An effectively unlimited long-term memory holding knowledge that can be used to overcome the limitations of working memory (Gabel, 1999).

5. Schemas held in long-term memory are used to structure knowledge by organising elements of information comprising lower order schemas into higher order schemas that require less working capacity (Pollock et al., 2002). 
6. Automation that allows schemas to be processed automatically rather than consciously in working memory, thus reducing working memory load (Pollock et al., 2002).

Figure 1. The first screen of Viscometer Simulator.

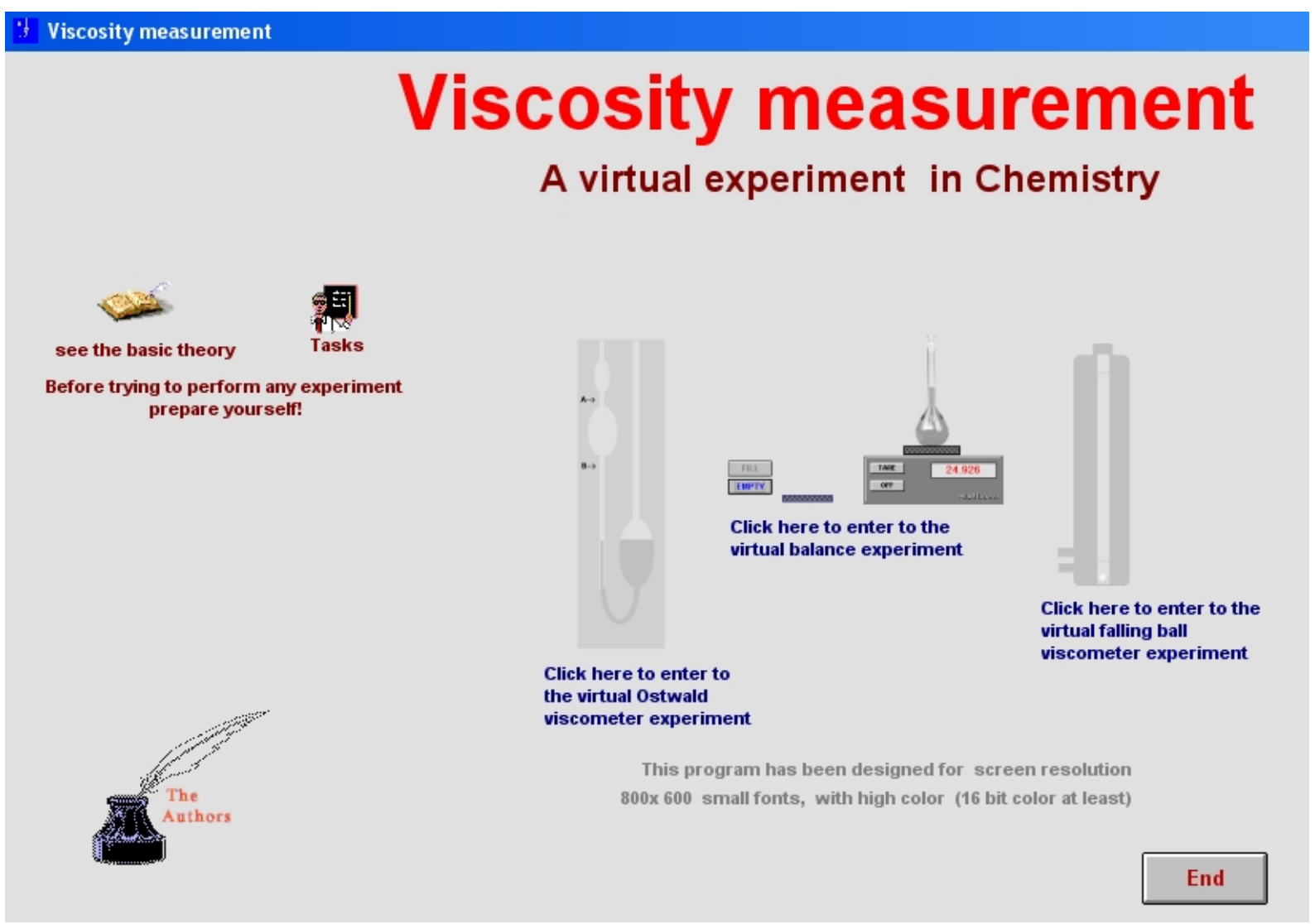

Following the above theory, we have designed educational software in which the virtual objects on the screen (Figure 1) look like the same objects in the real laboratory; this makes it easier to transfer what is learned here into real use and the software provides the users with information gradually, without overloading their memory. The program includes three virtual experiments, which are designed to introduce the students to density and viscosity determinations using two viscometer types, Ostwald and Falling-Sphere Viscometer. Relevant theory, tasks and introduction sections are available in every virtual experiment. The virtual experiments are:

- The Ostwald viscometer simulator for the determination of the viscosity of a liquid with an Ostwald capillary viscometer,

- The Falling-Sphere viscometer simulator for the determination of the viscosity of a liquid using a falling ball viscosity and

- The Balance simulator for the determination of the density of a liquid.

The users perform the virtual experiments using the same actions as in the real laboratory. Additionally, the user has the opportunity to choose the solution (a mixture of ethanol-water $0-100 \% \mathrm{w} / \mathrm{w})$ and its temperature $\left(15-30^{\circ} \mathrm{C}\right)$ when carrying out the experiment. Also, in the case of the Falling Ball viscometer, the students can choose pure liquids for their virtual experiments. 


\section{Integration of the educational software with the educational procedure}

We integrated the educational software into a pre-lab session. The basic points of the prelaboratory session were that students:

a) should not receive a huge amount of information at the same time;

b) should have enough time to process and save the useful information gradually;

c) should have had prior knowledge on which they could build their new knowledge and

d) the students participated in the teaching procedure actively.

We discussed the chemical phenomena and experimental procedure with students by posing questions to them. Students gave us answers based on their prior knowledge; this way we could determine whether the students had any misconceptions. When we identified student misconceptions, we used a Power-Point Presentation which included images and animations relevant to the topic, and we posed the same questions again so that students could process the new information better.

For example, in order to introduce students to viscosity theory, we posed questions about the liquid's properties and the liquid's motion. One of the questions was "what does it mean that a liquid flows, and how do you know that a liquid flows?" Students gave us several answers from which we realized that they had misconceptions about this topic, although they have been previously taught this subject during the course of their studies. For instance one student answered as follows:

Student: That means that it runs.

Teacher: What do you mean it runs, explain it or give us an example.

Student: When something runs, it is in motion and you need force to stop it.

Teacher: Ok you are partially correct, but you do not answer my initial question, maybe you should think at the microscopic level.

Student: What do you mean in a microscopic level? The molecules are like balls and as such they run like balls.

As the discussion continued and the students did not give us any clear answers, we used animations in a Power-Point Presentation to explain to them the motion of the liquid. Then we asked them again to explain how they now understood the liquid's motion in order to make students repeat it using their own words and consolidate it. Another area in which the students had misconceptions (where their knowledge was confused) was about the definitions of density, mass and concentrations. Using the above teaching procedure, we identified and clarified their misconceptions.

After that procedure, when the students understood the experimental theory better, they performed the virtual experiments in a classroom equipped with personal computers by using the simulation program. The students, who were divided into teams, suggested and designed their experimental procedures with our help, and after they processed the data on their Personal Computer (PC), they sent their results to our PC using LAN. The aim of this virtual experimentation was to get students to collaborate in order to design the experimental procedure and to obtain necessary data analysis and processing skills, as learning is more effective when students collaborate and participate actively during the teaching procedure (Shiland, 1999).

During the virtual experimentation, the simulator of the Falling-Sphere viscometer was used first to introduce students to the related experimental procedure for viscosity measurements. This was followed by the Ostwald viscometer simulator and the balance simulator, which were used to find the coefficient of viscosity of a solution. In this way the students received and processed the information about the experimental procedure gradually (they did not receive huge amount of information, such as the theory behind the experiment, the instrument manipulation, the sample preparation, the laboratory equipment, etc.). 
During the pre-lab session-virtual experimentation, students studied

a. the influence of temperature on the coefficient of viscosity and

b. the existence of intermolecular forces in the aqueous solutions of ethanol in different concentrations $(0-100 \% \mathrm{w} / \mathrm{w})$.

With the same approach as above (posing questions), we designed the experimental procedure jointly with the students. For example, we posed questions to students about the influence of temperature on the coefficient of viscosity. The students suggested to us an experimental procedure using the simulator, a spreadsheet program and the LAN.

\section{Experimental Procedure}

Specifically, using the viscosity simulator, every team determined the coefficient of viscosity of a specific ethanol-water solution for different temperatures $\left(15^{\circ} \mathrm{C}, 20^{\circ} \mathrm{C}, 25^{\circ} \mathrm{C}\right.$ and $30^{\circ} \mathrm{C}$ ). Next, every team collected its data in a spreadsheet on its PC, and a graph showing the relation between the coefficient of viscosity and temperature was plotted. At the end of the virtual experimentation, every team transferred its results to our PC using the LAN to give us 11 Excel files, one from each team, which referred to water-ethanol mixture (concentration range 0 to $100 \% \mathrm{w} / \mathrm{w}$ ) for different temperature values.

The next virtual experiment the students performed was the study of the intermolecular forces in the mixture ethanol-water. After the discussion about the intermolecular forces, the conditions in which intermolecular forces appear, the influence of intermolecular forces upon viscosity and its coefficient and how by using viscosity measurements we confirmed the existence of intermolecular forces in ethanol-water solutions, the students suggested to us the experimental procedure in order to calculate the number of solvent molecules that interact with one solute molecule using measurements of the previous virtual experiments.

Every team, which had access to our computer, transferred all data from the previous experiment to its computer using the internal network. Then every team selected a specific temperature and using the data of the coefficient of viscosity of the previous experiment, made the appropriate calculations to find the relationship between the molecules. The students produced graphs using a spreadsheet in order to find the relationship and obtained ratio between solvent and solute molecules.

After the end of pre-laboratory session, the EG students entered the laboratory in order to perform real experiments. Every team measured the viscosity coefficient of a specific solution of ethanol-water $(0-100 \% \mathrm{w} / \mathrm{w})$ at $25^{\circ} \mathrm{C}$ (every team performed only one experiment using the Ostwald viscometer). They exchanged their results and processed the experimental data as homework. We should point out that during the real laboratory, we did not explain anything about the experiments or how to perform them, thus the students performed the experiments without any instructions, we just told them to do only one experiment as they were trained on the pre-laboratory-simulation program. This was evidence that we did achieve one of our objectives, which was to increase the students' confidence when they enter a laboratory.

The CG students performed experiments in the laboratory following the teacher's instructions. Specifically, we introduced these students to viscosity without posing them any questions, and every team of students ( 2 students/team) performed 11 experiments using the Ostwald viscometer for the mixture of ethanol-water $(0-100 \% \mathrm{w} / \mathrm{w})$ at $25^{\circ} \mathrm{C}$. Finally, the students of the CG processed their experimental data as homework.

\section{The questionnaires}

At the end of the course, we distributed questionnaires to the students of both two groups (EG and CG). The aim of these questionnaires was to evaluate the students' knowledge about viscosity and to provide students with an opportunity to express their views about the teaching and learning method. The questionnaires were divided into two parts. The first part was 
common for both groups and referred to viscosity and chemical phenomena, and consisted of five open questions. Table 1 shows the questions. The researchers evaluated each answer using a one-to-six-points marking scheme: one point: = incomplete and wrong answer, six points: right and complete answer).

Table 1. The five chemical (content) questions of the first part of the questionnaire.

\begin{tabular}{|l|l|}
\hline Q1 & $\begin{array}{l}\text { Assuming that you would like to produce a shampoo, is it necessary to measure the coefficient } \\
\text { of viscosity in your solution? Explain your answer (think of what kind of properties your } \\
\text { shampoo should have). }\end{array}$ \\
\hline Q2 & $\begin{array}{l}\text { How can we measure the coefficient of viscosity of a solution, when using an Ostwald } \\
\text { viscometer? Explain exactly the experimental procedure. Why should we record the time } \\
\text { between the 'A marker' and the 'B marker' (markers on Ostwald viscometer before and after } \\
\text { small reservoir)? If we do not know the volume of the small reservoir, how can we calculate } \\
\text { the coefficient of viscosity? }\end{array}$ \\
\hline Q3 & $\begin{array}{l}\text { There is an inverse relation between the coefficient of viscosity and temperature. When the } \\
\text { temperature increases by } 1{ }^{\circ} C \text { the value of the coefficient of viscosity reduces by 2\%. Explain } \\
\text { why it happens and what that change means for someone who wants to produce a shampoo. }\end{array}$ \\
\hline Q4 & $\begin{array}{l}\text { Solution ethanol/water 50\% w/w and the mass of the solution is 150g. Calculate the moles of } \\
\text { ethanol and water and their molecular fractions. Can you describe the relationship between } \\
\text { mole fractions and the coefficient of viscosity? }\end{array}$ \\
\hline Q5 & $\begin{array}{l}\text { In a mixture ethanol/water, the experimental value of fluidity is different from the theoretical } \\
\text { value. Explain why this happens. Can you describe the conditions under which the } \\
\text { experimental value of a mixture will be the same as the theoretical value? Give one example of } \\
\text { a mixture in which the two above values are the same and one example in which they are not } \\
\text { the same. }\end{array}$ \\
\hline
\end{tabular}

The second part of the questionnaire distributed to EG students provided a number of statements, and students were asked to show the extent of their agreement on a one to six point, Likert-type scale: six-points = I strongly agree; one-point = I strongly disagree). The questions of this evaluation are given below in the Results section (see Table 3). In contrast, the second part of the questionnaire distributed to CG students asked them to express their opinion about the specific laboratory training.

\section{Results}

\section{First part of the questionnaire: Content knowledge}

We found that there was no significant difference between the answers of male and female students from either group of students.

For the chemical questions, we used analysis of variance (ANOVA) as a statistical analysis in order to compare the performances of the EG and the CG of students. ${ }^{1}$ The results of this comparison as well as the percent means and the percent standard deviations of the performances are shown in Table 2 .

It follows from Table 2 that on all five questions the EG outperformed the CG. Not only do all comparisons are statistically significant at $\mathrm{p}=0.000$, but also the absolute differences between the two means were large (from 23 to $29 \%$ ).

\footnotetext{
${ }^{1}$ Since in each case we compare two independent means, ANOVA here is equivalent to the student $t$ test for independent samples.
} 
Table 2. Scores (\%) on the chemical (content) questions of the experimental (EG) and the control group (CG) and statistical comparison by means of ANOVA.*

\begin{tabular}{cll}
\hline Question & Mean and SD results (\%) & ANOVA results $(\alpha=0.05)$ \\
\hline \multirow{2}{*}{ Q1 } & EG $(M=92, S D=9.8)$ & $F(1,86)=71.8, M S_{\mathrm{W}}=0.649$, \\
& CG $(M=68, S D=16.2)$ & $p=0.000$ \\
\multirow{2}{*}{ Q2 } & EG $(M=93, S D=13.1)$ & $F(1,86)=69.9, M \mathrm{~S}_{\mathrm{W}}=0.586$, \\
& CG $(M=70, S D=12.4)$ & $p=0.000$ \\
\hline \multirow{2}{*}{ Q3 } & EG $(M=88, S D=13.7)$ & $F(1,86)=75.5, M \mathrm{~S}_{\mathrm{W}}=0.617$, \\
& CG $(M=64, S D=12.4)$ & $p=0.000$ \\
\hline \multirow{2}{*}{ Q4 } & EG $(M=83, S D=14.8)$ & $F(1,86)=81.9, M \mathrm{~S}_{\mathrm{W}}=0.660$, \\
& CG $(M=57, S D=12.1)$ & $p=0.000$ \\
\hline \multirow{2}{*}{ Q5 } & EG $(M=71, S D=20.0)$ & $F(1,86)=26.9, M \mathrm{~S}_{\mathrm{W}}=1.05$, \\
& CG $(M=52, S D=13.6)$ & $p=0.000$
\end{tabular}

$* \alpha$ is the limit of significance level, $M \mathrm{~S}_{\mathrm{W}}$ is the mean square within groups, $F(\mathrm{a}, \mathrm{b})$ is the variance between groups $/ M S_{\mathrm{W}}, p$ is the significance level.

\section{Second part of the questionnaire: Student evaluation}

In this part of the questionnaire, the students of the EG were asked to assess the viscosity simulator, to give their impressions about the pre-laboratory and to evaluate how well the group exercise gave them the opportunity to cooperate with their fellow-students. We repeat that the students had to make a choice on a six-point Likert-type scale: strong agreement with a statement being six points, while strong disagreement being just one point). Table 3 has the questions and the descriptive statistics of the evaluation by the students, expressed as percent mean values and the corresponding standard deviations..

Table 3. Descriptive statistics* of the experimental group students' opinions about the simulation program, computer experience and the effectiveness of course.

\begin{tabular}{lcc}
\hline Questions for educational software and the pre-laboratory session & Mean (\%) & SD (\%) \\
\hline $\begin{array}{l}\text { Using the viscosity simulator, did you carry out the virtual experiments with } \\
\text { accuracy and repeatability? }\end{array}$ & 89 & 14.8 \\
\hline $\begin{array}{l}\text { Do you believe that you understood the theory behind the experiment before } \\
\text { you enter the laboratory? }\end{array}$ & 85 & 14.1 \\
\hline $\begin{array}{l}\text { Do you believe that you have obtained more computer experience after the } \\
\text { pre-laboratory session? }\end{array}$ & 91 & 9.8 \\
\hline $\begin{array}{l}\text { Did you have the opportunity to pose questions and have a discussion with } \\
\text { the teacher in the pre-laboratory session more interactive than during } \\
\text { traditional teaching? }\end{array}$ & 89 & 12.9 \\
\hline $\begin{array}{l}\text { How useful did you find the simulation program in order to understand the } \\
\text { theory behind the experiment? }\end{array}$ & 82 & 12.7 \\
\hline $\begin{array}{l}\text { Did you exchange views and information with other peers? } \\
\text { How useful did you find the collaboration with the other peers? }\end{array}$ & 83 & 13.2 \\
\hline $\begin{array}{l}\text { After the pre-laboratory session, did you feel more ready to carry out the } \\
\text { experiment in laboratory? }\end{array}$ & 85 & 13.1 \\
\hline $\begin{array}{l}\text { How do you find the idea to have other similar simulation programs created } \\
\text { about other chemistry phenomena and experiments? }\end{array}$ & 86 & 13.1 \\
\hline
\end{tabular}

* Percent mean values and percent standard deviations derived from students' choices in a Likert-type scale (1-6) (1: not al all; 6: very much). 
In all cases, the EG students strongly agreed (mean values from 82-91\%). The students valued the opportunity to question the teacher in the pre-laboratory session, and they found the simulation program useful in order to understand the theory behind the experiment. As a result they felt more confident when they entered the laboratory. They also found useful the collaboration with their peers. Finally, they agreed with the idea to have similar simulation programs created about other chemistry phenomena and experiments.

In their own second part of the questionnaire, the CG students were asked to express their opinion concerning their laboratory training. These students had to perform the experiment several times and thus they did much more experimental work, which they found tedious enough and eventually grew tired of. Hence, in the second part of their questionnaire, their response was not as favourable, as many complained that repeating the same experiment several times was pointless, and that routine procedures like repositioning and cleaning of the capillary were tiresome enough. On the other hand, the EG performed the experiment only once, therefore a similar negative attitude towards the experimental procedure was not observed. In conclusion, by taking into account the students' responses we realize that students find more constructive and less tiresome spending time to both pre-laboratory and laboratory sessions rather doing three full hours of experimental work at the lab only.

\section{Discussion}

"Learning only occurs when students create their own understanding; but teachers are needed to create the environment in which this can happen" (Shiland, 1999). In this investigation, the EG students discussed with the teacher more thoroughly topics relevant to viscosity. By using the simulator and a Power-Point presentation they could be better familiarized with the theory behind the experiments before they entered a real laboratory. As we posed questions to these students, so that discussion could take place, we could identify students' misconceptions and clarify them. For example, when we asked students about the difference between the density and the mass, the students were confused; they could not explain the concepts of mass and density, although they knew the mathematical relationship between the two concepts. Therefore, by using the Power-Point Presentation we projected some appropriate images and asked the students to explain them to us. Moreover, by using the balance simulator, we asked them to calculate the mass and the density of several solutions and to explain the difference in their results. In this way the students could come to a personal understanding through the virtual experiments and they had the opportunity to understand better the theory behind the experiment before they entered the laboratory.

In addition, the EG students had the opportunity to perform both virtual experiments in pre-laboratory session and real experiments in the laboratory, in order to consolidate the experimental procedure. During the pre-laboratory session, we did not give the students exact instructions, but the students suggested to us the experimental procedure and we posed to them questions about it in order to get students to think about it in greater depth. Thus, the students participated actively in the experimental design. This explains the significant difference between the performance of the EG and the CG, in which the students used only 'recipes labs', followed the instructions step-by-step and performed the experiment mechanically. The above procedure demonstrates that the "learning of science is about the student being initiated into the ideas and practices of the scientific community and it is not the simple transmission of facts from teacher to student, but a continuous and active process on both sides" (Shiland, 1999).

Using the viscosity simulator, the EG students performed the virtual experiments with accuracy and repeatability and therefore they could perform numerous experiments easily and with accuracy and they were focused on the analysis, process and the interpretation of 
experimental data. As EG students declared after the pre-laboratory session, they felt ready to perform the corresponding laboratory activity and were not intimidated by the laboratory environment and experiment. On the other hand the CG students followed the instructions step-by-step using 'recipes labs' without any opportunity to clarify their misconceptions and as they struggled to operate the equipment during the laboratory session, they failed to make important observations, and therefore gathered poor data (Johnstone and Al-Shuali, 2001). The CG students just carried out the experiments in the laboratory without analysing the experimental data and processed the experimental data as homework.

"Learning has a social component. Knowledge construction is primarily a social process in which meaning is constructed in the context of dialogue with others. Learning is aided by conversation that seeks and clarifies the ideas of learners" (Shiland, 1999). In our investigation, the EG students, who were divided into teams, shared data, exchanged views explored several different aspects of the same questions, and students with more computer experience helped their less experienced colleagues. Additionally, as they exchanged data using the LAN, the whole class worked as a team and every wrong result influenced the final conclusions. In a classroom usually there are students who are shyer than others and they are afraid to address questions directly to the teacher. We observed that there were long conversations between the EG students before giving us their final answers or their experimental results. This collaboration helped them to exchange information and learn from their peers, or because they had the opportunity to ask us questions, they could clarify their misunderstandings. During this collaboration the students had the opportunity to process only a little information at a given time and to think on a specific topic. Therefore, they could develop the critical thinking instead of attending a lecture passively. This collaboration in combination with the use of the simulator in the pre-lab session led them to perform the experiments in the real laboratory without following the teacher's instructions mechanically line-by-line without thinking. According to Kirschner (2001), collaborative learning supports the use of the effective learning methods (make explicit, discuss, reason, etc.) while allowing for the acquisition of essential social communications skills.

A simulator is a multimedia application, which can be used as a tool but cannot by itself replace an instructor and the laboratory training. Teachers will always be essential to address the human, creative and artistic parts of teaching, and this makes a major difference in how well students learn and more importantly how well they build up their knowledge (Bunce, 2001). Consequently, we adopted an active, stimulating role by posing a problem to the learners where the teacher was very much a facilitator rather than a direct provider for student learning. Students of the EG had to think and to suggest to us the experimental procedure they should follow for every virtual experiment and to perform the real experiments in the laboratory after the pre-laboratory session; therefore, we increased their confidence for when they enter the laboratory. This was obvious as these students entered the laboratory; they performed the experiments without our instructions. In this way, learning takes place in an active mode and the teacher has a facilitator's role rather than a being 'sage on the stage' (Kirschner, 2001).

During the course of undergraduate studies all students should be able to select and use the appropriate software for a particular task: spreadsheets, which facilitate calculations, and scientific graphic packages, which can visualise the meaning of a figure. The easiest way to introduce the computation into a chemistry curriculum is by simulation and data reduction programs (Zielinski and Swift, 1997). In this investigation, as the EG students performed the virtual experiments, they could obtain experience on the information technology such as the use of Excel and the LAN. Also, a recent survey conducted in England (Duckett et al., 1999), tried to identify the key skills which were mostly needed by recently employed chemistry graduates, and how well their chemistry courses have prepared them in order to use these 
skills in their job. The chemists who participated in this survey, pointed out the essential technical skills which should be included in chemistry courses in order to better prepare the chemists for their future employment. Some of these were: computing/IT, team working, problem solving and communication skills. Our investigation was focused on the acquisition of some of these skills.

\section{Conclusions}

The integration of the simulation program into pre-laboratory session was inspired by the cognitive load theory of learning and constructivism. During the pre-laboratory session the teacher discussed with students of the experimental group (EG) the relevant chemical phenomena, designed experimental procedure with students and encouraged team-work by utilising the Personal Computer (PC) and Local Area Network (LAN), which allowed students to solve more complex problems. The result of this procedure was that EG students obtained experience on the design of the experimental procedure, the use of spreadsheets and LAN and the interpretation of the data. After the pre-laboratory session, these students were able to perform experiments in a chemical laboratory without any further guidance. In contrast to those following traditional laboratory training, these students understood better the theory behind the experiment as they had time to connect the common points between new knowledge and their previous knowledge and to clarify any misconceptions. With the integration of computer applications into a chemical laboratory, the teachers had the opportunity to create a more stimulating and motivating teaching environment where learning could be both challenging and, at the same time, pleasing.

\section{References}

Bennett S.W. and O'Neale K., (1998), Skills development and practical work in chemistry, University Chemistry Education, 2, 58-62.

Bodner G.M., (1986), Constructivism: a theory of knowledge, Journal of Chemical Education, 63, 873-878.

Bodner G., Klobuchar M. and Geelan D., (2001), The many forms of constructivism, Journal of Chemical Education, 78, 1107-1115.

Bunce M.D., (2001), Does Piaget still have anything to say to chemists?, Journal of Chemical Education, 78, 1107-1121

Clow D., (1998), Teaching, learning, and computing, University Chemistry Education, 2, 21-28.

Clow D. and Garratt J., (1998), Computer simulations: creating opportunities for science writing, University Chemistry Education, 2, 51-54.

Domin D.S., (1999), A review of laboratory instruction styles, Journal of Chemical Education, 76, 543-547.

Duckett S.B., Garratt J. and Lowe N.D., (1999), Key skills: what do chemistry graduates think? University Chemistry Education, 3, 1-7.

Fermann J.T., Stamm K.M., Maillet A.L., Nelson C., Codden S.J., Spaziani M.A., Ramirez M. and Vining W.J., (2000), Discovery learning using chemland simulation software, The Chemical Educator, 5, 31-37.

Gabel D., (1999), Improving teaching and learning through chemistry education research: a look to the future, Journal of Chemical Education, 76, 548-554.

Garratt J., (1997), Virtual investigations: ways to accelerate experience, University Chemistry Education, 2, 19-27.

Johnstone A.H. and Al-Shuali A., (2001), Learning in the laboratory; some thoughts from the literature, University Chemistry Education, 5, 42-51.

Johnstone A.H., (2000), Chemical education research: where from here? University Chemistry Education, 4, 34-38. 
Johnstone A.H., (1997a), ...And some fell on good ground, University Chemistry Education, 1, 8-13.

Johnstone A.H., (1997b), Chemical education, science or alchemy? Journal of Chemical Education, 74, 262-268.

Johnstone A.H. and Wham A.J.B., (1982), The demands of practical work, Education in Chemistry, 19, 71-73.

Kirschner P.A., (2001), Using integrated electronic environments for collaborative teaching/learning, Research Dialogue in Learning and Instruction, 2, 1-9.

Mayer R.E. and Moreno R., (2002), Aids to computers-based multimedia learning, Learning and Instruction, 12, 107-119.

Nicholls B.S., (1999), Pre-laboratory support using dedicated software, University Chemistry Education, 3, 22-27.

Papadopoulos N., Pitta A.T., Markopoulos N., Limniou M., Lemos M.A.N.D.A., Lemos F. and Freire F.G, (1999), Viscosity measurement: a virtual experiment, Journal of Chemical Education, 76, 1600.

Pollock E, Chandler P. and Sweller J., (2002), Assimilating complex information, Learning and Instruction, 12, 61-86.

Preece J., Rogers Y., Sharp H., Benyon D., Holland S. and Carey T., (1994), Human-Computer Interaction: Concepts and Design, Addison-Wesley, London.

Quinn C.N. and Wild M., (1998), Supporting cognitive design: lessons from human-computer interaction and computer-mediated learning, Education and Information Technologies, 3, 175185.

Ritter D and Johnson M., (1997), Virtual titrator, a student-oriented, instrument, Journal of Chemical Education, 74, 120-123.

Robinson W.R., (2000), A view of the science education research literature: scientific discovery learning with computer simulations, Journal of Chemical Education, 77, 17-18.

Robinson W.R., (2002), Cognitive theory and the design of multimedia instruction, Journal of Chemical Education, 81, 10-13.

Shiland, T.W., (1999), Constructivism: the implication for laboratory work, Journal of Chemical Education, 76, 107-108.

Thomas R. and Neilson I., (1995), Harnessing simulations in the service of education: the interact simulation environment, Computers and Education, 25, 21-29.

Towns M.H., (2001), Kolb for chemists: David A. Kolb and experimental learning theory, Journal of Chemical Education, 78, 1107-1115.

Waller J.C. and Foster N., (2000), Training via the web: a virtual instrument, Computers and Education, 35, 161-167.

Zielinski T.J. and Swift M.L., (1997), What every chemist should know about computers II, The Chemical Educator, 2, 258-262. 